\title{
Aprendizagem organizacional e empreendedorismo social na atual configuração do mundo do trabalho*
}

\author{
Valentina Medrano Coley' \\ Universidad de São Paulo (Brasil)
}

Recibido: enero 17 de 2015 - Revisado: abril 17 de 2015 - Aceptado: mayo 20 de 2015

Referencia formato APA: Medrano, V. (2015). Aprendizagem organizacional e empreendedorismo social na atual configuraçáo do mundo do trabalho. Revista Cientifica Guillermo de Ockham, 13(1), 67-78.

\section{Resumo}

O seguinte artigo aborda a articulação entre dois conceitos atuais que se inscrevem no contexto laboral latino-americano, a Aprendizagem organizacional, processo cognitivo-social pelo qual os membros da organizaçáo constroem, estabelecem práticas e ideologias institucionalizadas. E, o Empreendedorismo social como nova forma de configuração do trabalho que busca a transformação e emancipação social, se apresentando como um modelo de agenciamento alterno ao capitalismo. Este artigo foi realizado por meio de uma revisão de literatura, considerando como fontes principais, os periódicos e revistas latino-americanas inscritas nos campos de estudo, Psicologia e administração.

Palavras-chave: Aprendizagem Organizacional, Empreendedorismo Social, Mundo do Trabalho

\section{Organizational learning and social entrepreneurship in a current setting of the World of Work}

\section{Abstract}

The primary aim of this paper is to approach the articulation between two concepts which play a role in the current context of the Latin-American labor force, organizational learning, the Cognitive-Social process through which members of an organization internalize and create institutionalized practices and ideologies and social entrepreneurship as a new form of work setting that seeks social transformation and emancipation, presenting itself as an alternative model of action to capitalism. This paper was accomplished through a literature review, considering Latin-Americans journals and Magazines - inscribed in the study fields, Psychology and Management.

Keywords: Organizational Learning, Social Entrepreneurship, World of Work

\footnotetext{
* Este artículo se deriva del proyecto de investigación Aprendizagem organizacional em organizaçóes baseadas em empreendedorismo social da Colômbia e do Brasil.

1. Psicóloga y candidata a doctorado en Psicología Social y del Trabajo en la Universidad de Sáo Paulo (Brasil).E-mail: valentinamedrano@usp.br valentinamedranocoley@hotmail.com. Dirección Postal: Instituto de Psicología-USP Av. Prof.Mello Moraes,1721-Bloco G-s.13
} 


\section{Aprendizaje organizacional y emprendimiento social en las configuraciones actuales del mundo del trabajo}

\section{Resumen}

El siguiente artículo tiene como principal objetivo abordar la articulación entre dos conceptos que se inscriben en el actual contexto laboral latinoamericano, el aprendizaje organizacional, proceso cognitivo-social por medio del cual los miembros de una organización internalizan e construyen prácticas e ideologías institucionalizadas y el emprendimiento social, como nueva forma de configuración del trabajo que busca la transformación y emancipación social y se presenta como un modelo de acción alterno al capitalismo. Este artículo fue elaborado por medio de una revisión de literatura, en la que se consideraron como fuentes principales periódicos y revistas latinoamericanas inscritas en los campos de estudio, psicología y administración.

Palabras clave: aprendizaje organizacional, emprendimiento social, mundo del trabajo

\section{Introdução e objetivos}

O trabalho historicamente tem sido paradoxal, por um lado como elemento de humanizaçáo e transformação individual e social, atividade humana pela qual o homem constrói sua cultura e revela sua subjetividade e como possibilidade de se converter numa atividade alienante $\mathrm{e}$ inibidora das potencialidades do ser humano (Marcuse, 1955).

Embora o trabalho se configure como forma de organização social, além de determinar ou influenciar o modelo de subjetividade preponderante, também dele necessita para sustentar-se, existindo uma forte relaçáo entre trabalho e subjetividade, relação recíproca enquanto influências e determinaçôes.

$\mathrm{Na}$ contemporaneidade, as transformaçóes econômicas, sociais, políticas e culturais têm afetado os diferentes significados e configuraçôes do trabalho. Ante esta dinamicidade é necessário analisar e aprofundar a constituição desta subjetividade e do trabalho desde um olhar multicausal (nunca linear, nem unidirecional) e considerando o ritmo frenético e sem precedentes dos movimentos capitalistas (Giddens, 2002).

Ao conscientizar sobre este momento histórico percebese uma invalidação dos grandes discursos ou "metarrelatos" que funcionavam como margens ordenadoras de todas as atividades humanas. Esta invalidação influenciada por fenômenos como a globalizaçáo, na compreensão mais ampla do termo como fenômeno histórico-social, a crise econômica vivenciada desde o ano 2008 com grandes repercussóes na estrutura político-econômica dos países do primeiro mundo e indiretamente afetando os nossos países latinos- americanos, e a implantação do individualismo como produto da sociedade de consumo - coloca ao ser humano necessidades de busca cada vez maiores do "ter" em detrimento do "ser" e finalmente, a transformação das figuras e instituiçóes (Religiáo, Família patriarcal, Trabalho), que detinham autoridade e padronizavam os comportamentos socialmente aceitáveis.

Apesar desta realidade, acredita-se que o contexto possibilita acolher uma visão do homem enquanto construtor da cultura por meio do trabalho, ao mesmo tempo em que o mesmo sujeito é constituído pela realidade objetiva na qual está inserido. Sobre esta reflexão este artigo tem como principal objetivo reconhecer a possível articulaçáo entre dois processos relacionados com o mundo do trabalho: Aprendizagem organizacional e Empreendedorismo social.

A aprendizagem organizacional, processo que hoje em dia exige uma mirada caleidoscópica, reconhecendo suas particularidades e transformaçôes através de diferentes campos de estudo pelos quais o conceito tem evoluído figura como um processo presente na interaçáo pessoaorganizaçáo.

Nesta abordagem surgem diferentes desafios relacionados com os pressupostos sociais, filosóficos e humanistas que configuram a aprendizagem, e os aspectos subjetivos associados ao ato de aprender. Trata-se, portanto, de um bem social valorizado por uma sociedade que não gira exclusiva e prioritariamente em torno da produção econômica e material, e tem valorizado nos últimos anos os processos emergentes do contexto organizacional.

Observam-se grandes transformaçôes nas relações econômicas, sociais e políticas do trabalho, ante esta realidade têm surgido novas configuraçóes dentro deste, e como caso especifico, o empreendedorismo social. Esta configuraçáo 
emerge de uma açáo reflexiva sobre as características da contemporaneidade e como modelo de trabalho alternativo a modelos puramente capitalistas (Dees, 2001).

Singer, (2004) assinala o processo desenfreado de crescimento voltado, basicamente, para o modelo econômico capitalista. Levantando a necessidade de toda pesquisa dentro das ciências sociais de compreender os contornos deste terreno histórico, ou seja, o mundo em que vivemos. Dentro destes contornos como é proposto pelo autor, é fundamental reconhecer o capitalismo como a forma de produção dominante, embora se considere que possa haver outros tipos de modelos e configuraçôes de trabalho que buscam atuar em paralelo ao capitalismo.

A gestão social, a economia solidária, a autogestão e o modelo societal são algumas das identificadas como formas paralelas, na gestão social segundo o interesse deste artigo, encontramos o movimento chamado de Empreendedorismo Social, cuja importância está em se apresentar como uma nova dinâmica socioeconômica, caracterizado por sua natureza coletiva e objetivos de transformação social, levando a uma diferenciação com o modelo tradicional, o empreendedorismo empresarial, nascido dentro das margens do capitalismo, com características individualistas e de lucro econômico.

No final dos anos de 1990, o empreendedorismo social na América latina, emergiu da constatação dos cidadãos de um visível paradoxo entre globalizaçáo e pobreza, constataçáo que evidencia novos e velhos desafios para o desenvolvimento humano e a emancipação social além da necessidade de procurar outras visóes sobre uma sociedade mais sustentável, humana e justa.

Bose (2004) assinala fatos e condiçóes que facilitaram a emergência do empreendedorismo social como meio de transformação social, entre eles; o surgimento da pobreza perceptiva; o crescimento e intervençáo do Terceiro Setor e a polêmica em torno da mudança da lógica de intervençáo dessas organizaçôes, que, nos anos de 1960 e 1970, tinham uma postura mais contestatória, e, após os anos de 1980, apresentam uma nova racionalidade, menos contestatória, e mais participativa e propositiva, fato que altera as relaçóes entre Sociedade Civil e Estado.

É no epicentro desses acontecimentos que o empreendedorismo social começa atuar como forma de inovação, dentro da gestão social, figurando como um modelo de ação de emancipação social, desenvolvimento humano, e em alguns casos ele se dá mais como manutenção do status quo e da desigualdade como é exposto por Oliveira, (2004).
Estas configuraçôes, formas e conteúdos relacionados com o empreendedorismo social, evidenciam uma necessidade de ampliar a compreensáo vigente, levando-a para marcos maiores de ordem psicossocial, cultural e econômica.

Tomando o empreendedorismo social como um novo contexto laboral possibilita enxergar processos de ordem psicossocial como é a aprendizagem organizacional, a qual permite ressaltar a complexidade das intersubjetividades humanas, as aprendizagens que emergem nas práticas e que poderiam ser fundamentais para entender o gênesis, desenvolvimento e agenciamento da organização empreendedora Rosero, (2009).

A aprendizagem na perspectiva social remete a fenômenos como interação, troca de experiências e diálogo, características que são fundamentais para proporcionar a inclusão social, a reduçáo da pobreza, o desenvolvimento local, atos de reflexividade, de engajamento e de participaçáo dos cidadáos. O conceito de aprendizagem organizacional surge na literatura articulado com o empreendedorismo social conceituando-o como processo facilitador para o desenvolvimento de açóes capazes de promover o crescimento e consecução dos objetivos sociais.

Neste artigo tomaremos o conceito de empreendedorismo social como processo sociocultural, pelo qual se pretende abordar o fenômeno através da análise e de perspectivas e autores que focalizam o processo desde marcos sócio-culturais, entendendo o fenômeno dentro de comunidades de prática.

Busca-se identificar a dinâmica das relaçóes entre diversos atores, envolvidos a partir de redes sociais, onde são geradas diversas estruturas organizacionais, fóruns, parcerias, alianças, conselhos, consórcios, ocorrendo uma relação de cooperação, confronto e interaçáo. Neste universo sáo produzidos como resultados novos conhecimentos, ferramentas, tecnologias e inovaçóes, (Souza-Silva \& Schommer, 2008).

Tomaremos como base a capacidade de aprendizagem de indivíduos e organizaçóes para o desenvolvimento, tanto no âmbito individual, quanto organizacional e territorial (Souza-Silva \& Schommer, 2008). Neste sentido, compreender o processo de aprendizagem como conhecimento gerado e específico, onde se entende que as próprias organizaçóes aprendem e constroem espaços de relaçáo social e vínculos de relacionamento institucional através de um conjunto de açóes dentro de especificidades culturais, políticas e históricas. 
As organizaçôes latino-mericanas que decidem mudar a realidade social mediante ações focadas na melhora da qualidade de vida de um grupo especifico de pessoas, precisam da construçáo de uma visão e plano de açáo compartilhado. Para incentivar o compromisso a longo prazo por parte dos membros, precisa-se de uma internalizaçáo de habilidades e ideologias relacionadas à transformação social e as quais caracterizam a cultura organizacional.

O processo de aprendizagem organizacional dentro de uma organizaçáo empreendedora social possibilita a transição de perspectivas individuais para objetivos coletivos. Abordar este processo psicossocial neste texto pretende analisar a sua articulaçấo em empreendedorismos sociais e a sua capacidade criar compromisso nos membros com os objetivos organizacionais.

\section{Método: Método de localização, seleção de bibliografia}

Em primeiro lugar é importante situar o desenvolvimento deste artigo no período dos anos de 2013-2014, sendo uma revisão bibliográfica que tem como finalidade examinar autores e perspectivas sócios históricas sobre ambos os conceitos centrais; Aprendizagem organizacional e empreendedorismo social. A revisão realizada foi organizada e desenvolvida da seguinte forma: Revisão de fontes primárias ou originais: Livros, revistas científicas, conferências latino-americanas com predominância de estudos realizados nos países Colômbia e Brasil e finalmente uma seleçáo sobre autores que mostraram posicionamentos epistemológicos sócio-históricos.

\section{Desenvolvimento e discussão teórica}

$\mathrm{Na}$ análise e desenvolvimento histórico dos conceitos e suas diferentes abordagens e compreensões em diferentes contextos acadêmicos, se faz pertinente nesta parte do artigo focalizar nos principais significados associados a os conceitos chaves: Aprendizagem organizacional e Empreendedorismo social.

\section{Conceitualização da aprendizagem como processo organizacional}

A aprendizagem é um processo psicológico essencial para a sobrevivência do homem ao longo de toda a sua existência. É através da aprendizagem que os seres humanos garantem sua sobrevivência e adaptabilidade ao meio ambiente, bem como seu desenvolvimento e expectativas de crescimento pessoal e autorrealização.

O termo aprendizagem etimologicamente vem do latim Apprehendere, composto pelo prefixo ad (para) e do prefixo Prae- (antes) e do verbo Hendere (atrapar, agarrar) associada com a planta hedera, "hera", Planta trepadeira que se agarra, se prende às paredes para poder crescer. "levar para junto de si", metaforicamente "levar para junto da memória”. Trata-se de um processo universal, estudado por diferentes campos do conhecimento, porém nesta parte do texto o principal objetivo será realizar uma análise, focado desde a Psicologia.

São muitos os estudos sobre como os homens aprendem, as diferentes posturas e paradigmas que tem evoluído historicamente tem tecido concepçóes de aprendizagem em diversas teorias, também denominadas correntes epistemológicas. No longo da história da Psicologia, podem-se organizar pedagogicamente quatro perspectivas que tem estudado o processo e a teoria da aprendizagem. Primeiramente a perspectiva biológica assume o comportamento humano como resultado fisiológico e de anatomia, dentro de um escopo genético e significantemente neurofisiológico, onde as mudanças no indivíduo acontecem pela estimulação do meio ambiente.

Esta perspectiva biológica da aprendizagem pode ser desdobrada em duas vertentes: a comportamental, uma das primeiras associaçóes feitas pela psicologia foi dentro desta linha, sendo o norte-americano Burrhus Frederic Skinner o principal representante do behaviorismo que se trata de uma corrente psicológica que procura explicar o comportamento humano como resultado das influências dos estímulos do meio ambiente. A principal contribuição de Skinner para a Psicologia foi o conceito de comportamento operante que descreve um tipo de relação entre as respostas dos organismos e o ambiente.

Associando à aprendizagem e mudança, definindo a aprendizagem como uma modificaçáa de certo modo contínua do comportamento, poder-se-ia identificar definiçôes que ressaltam a aprendizagem como uma mudança relativamente permanente do comportamento potencial como resultado do reforço e do ambiente (Hergenhan, 1982).

Dentro desse paradigma comportamental a aprendizagem cumpre o papel de capacitar o indivíduo para se adaptar as dinâmicas exigidas pelo ambiente. A outra vertente localizada nesta perspectiva biológica é (a) da aprendizagem social, embora neste olhar teóricos como Bandura (1982), já reconhecem elementos internos dos indivíduos

$<$ Universidad de San Buenaventura, Cali - Colombia 
como participantes do processo de aprendizagem, este olhar continua dentro de uma visão comportamental, devido ao protagonismo que coloca nas experiências diretas com o meio ambiente para que a aprendizagem aconteça e suas respectivas consequências. Logo, a aprendizagem ativa ocorre mediante a reflexáo do comportamento e avaliação das suas consequências. As consequências dos comportamentos, por sua vez, têm como funções informar os efeitos das açôes, motivar comportamentos antecipadamente e reforçar, Feist e Feist (2008).

Outra perspectiva desenvolvida pela Psicologia éa Cognitiva, esta compreende o comportamento como produto das estruturas e processos mentais. Este olhar tem fortes associaçóes com o processamento de informações, construção social e aprendizagem aplicada. Macksoud, (2002) destaca que esta perspectiva cognitiva da aprendizagem é dominante atualmente em diversos contextos onde se pretende estudar processos de aprendizagem.

A quarta perspectiva, a sociocultural foca no contexto evidenciando que a cultura é um influenciador do comportamento e da aprendizagem humana. Autores representativos na história da psicologia como è Jean Piaget o qual apresentava uma postura oposta a visões unicamente biológicas revela que a aprendizagem é uma construção ativa mediante a interação do sujeito e a cultura.

Entender o conhecimento como construção, não constitui uma cópia da realidade segundo Piaget, (1986), o indivíduo transforma a realidade objetiva com base em seus esquemas mentais. $\mathrm{O}$ individuo seleciona, interpreta e organiza a informaçáo do contexto de acordo com suas possibilidades cognitivas- as quais são resultado do processo de construção ontogenético.

Dentro desta perspectiva é localizada também a teoria sócio-histórica de Vygotsky, este autor entendia que a aprendizagem não era uma mera aquisição de informações, e não acontecia a partir de uma simples associação entre ideias armazenadas na memória, se tratando entáo, de um processo ativo e interpessoal.

Epistemologicamente a aprendizagem tem contado com um enorme leque de abordagens e desenvolvimentos teóricos, os quais desde suas particularidades têm gerado associações, conceitos e descriçōes sobre como os seres humanos aprendem ao longo do seu desenvolvimento. A complexidade do processo é reconhecida de forma ampla, autores como Pawlowsky, (2001), expóe uma necessidade de sistematizar os diferentes estágios ou níveis onde o processo de aprendizagem acontece, já que conforme a tese do autor, compreender a aprendizagem como processo individual e basicamente mental, limita seu desenvolvimento conceitual e epistemológico.

\section{Aprendizagem como processo multinivel}

Concordando com a abordagem de Pawlowsky (2001), o processo de aprendizagem é dinâmico e baseado em um sistema aberto que é composto por elementos de naturezas diversas, pois além do individual e subjetivo inclui fatores de acontecimento em diferentes contextos.

Enfatizamos a aprendizagem no foco de análise da experiência do trabalho que inclui diferentes níveis (individual, grupal e organizacional) sendo processos interdependentes que podem acontecer simultaneamente.

Este autor identificou e propôs um arcabouço conceitual para a compreensão e a gestão do conceito. $\mathrm{O}$ arcabouço proposto por ele tem por objetivo organizar, sistematizar e agrupar em níveis de aprendizagem os quais apresentam diferentes unidades de análise.

Os níveis individual, grupal, organizacional, propostos pelo autor, representam uma grande contribuição, que nos permite uma categorização pedagógica que consente a compreensão de diferentes eixos de análise que intervém no processo de aprendizagem nas organizaçóes que é o objetivo central no nosso estudo.

O nível individual coloca que a unidade de aprendizagem será sempre o indivíduo, este e sua estrutura cognitiva são os que tornam possível o conhecimento, no nível grupal, o processo caracteriza-se por ser coletivo e histórico, os conteúdos compartilhados pelo grupo de indivíduos determina o que é aprendido e o que não é, neste nível a legitimidade provém do mesmo grupo. Os grupos representam os espaços onde a visão de mundo das pessoas é compartilhada, medida, legitimada e influenciada pelo conjunto de indivíduos que dela participam.

Finalmente o nível organizacional retoma as características, Coletivo e histórico, mas transcende o processo de aprendizagem até a noção de institucionalização e coloca a organização como agente ativo que aprende e se transforma de acordo com a experiência e inter-relaçáo das subjetividades dos membros. Para Pawlowsky, (2001), a aprendizagem organizacional deve ser entendida como distinta da aprendizagem individual, destacando-se o nível grupal, pois o grupo ou time funcionam como "portáo de entrada” para a aprendizagem organizacional.

Poder-se-ia considerar além da contribuição pedagógica antes mencionada, uma contribuiçâo epistemológica 
referente à unidade de análise que possui cada nível sistematizado por este autor.

Sendo para este artigo o interesse principal uma abordagem social e institucional do processo de aprendizagem, serão focadas as análises e reflexóes no nível organizacional por ser neste nível onde as características institucionais são consideradas como essenciais para o processo de aprendizagem dentro do contexto organizacional. Nesta análise da historicidade da aprendizagem organizacional é perceptível que este é um tema que já possui muitos estudos e diversas abordagens ontológicas e epistemológicas que se refletem em um campo multiparadigmático, Antonello, (2005).

Divulgação e crescimento teórico: interfaces entre a Psicologia e a Administração

Estudar a aprendizagem organizacional dentro de uma interface de autores e teorias de dois campos de conhecimento como são a psicologia e a administração, ressaltando a natureza das organizaçóes como espaços onde os seres humanos podem ampliar suas possibilidades de aprendizagem e se mobilizar através de novos modelos de pensamento que se sustentam na liberaçáo da aspiraçáo coletiva. (Easterby-Smith \& Araujo, 2001).

Historicamente o papel da Psicologia na industrializaçáo começa devido à demanda e necessidades da gerência científica, de técnicas psicologias que facilitarem o controle da conduta por parte da administraçáo. O surgimento da Psicologia Organizacional especificamente esteve caracterizado pela utilização de técnicas e teorias comportamentalistas, nas quais a aprendizagem é entendida como uma conduta observável e relativamente permanente no tempo e espaço.

É então dentro desta tendência comportamental que pode ser identificado o primeiro estudo sobre aprendizagem organizacional, Cyert e March em 1963, (foram) os primeiros autores a referenciar o conceito na obra Behavioral Theory of The Firm, em centram a Aprendizagem Organizacional como um processo de adaptação da organizaçáo ao entorno.

Posteriormente Chris Argyris e Schön, (1978), definiram a aprendizagem organizacional como a detecçáo e correçâo de erros pertencentes à dinâmica organizacional. Fiol e Lyles, (1985) explicaram a aprendizagem como o processo de melhorar açôes através de melhor conhecimento e compreensão dos processos organizacionais. Já para Dodgson, (1993) a aprendizagem organizacional é a forma como as empresas constroem, suplementam e organizam o conhecimento e as rotinas em torno das suas atividades dentro das suas culturas e se adaptam e se desenvolvem produzindo eficácia organizacional e melhorando a utilizaçáo de competências amplas nas suas forças de trabalho.

Autores como Loiola e Bittencourt Bastos, (2003) numa revisão bibliográfica mostram a partir do nível de produtividade acadêmica relacionada com a aprendizagem organizacional, uma especial e expressiva interface entre Administração e Psicologia, onde em 53,5\% das referências utilizadas nos artigos analisados pertenciam a estes campos.

"Grande parte da discussáo que cerca o conceito de aprendizagem organizacional advém, exatamente, dessa transposição de um conceito classicamente utilizado para explicar processos no nivel individual, para a compreensáo de processos organizacionais. É compreensivel, portanto, que a Psicologia forneça os princípios básicos desse processo e que tais principios sejam tomados como ponto de partida para a análise do que ocorre nas organizaçôes." (Loiola \& Bittencourt, 2003, p. 187).

Dentro de esta mesma linha, Argyris e Schön, (1978) desenvolveram certa quantidade de conceitos importantes em relação à aprendizagem Organizacional como foram à distinção entre laço único e duplo de aprendizagem. $\mathrm{O}$ laço único envolve a detecção e correção do erro, dentro de um conjunto de variáveis. Esta teoria enfatizava a aprendizagem de laço único como relativa á mudança incremental, buscando-se um feedback contínuo sobre métodos e regras implementadas para conseguir fazer as mudanças de forma imediata. O laço duplo por sua parte é mais associado a transformaçóes radicais, com base em revisóes profundas de processos e atividades do corpo central de colaboradores.

Duncan e Weiss, (1979) e Hedberg, (1981), deram de certa forma continuidade a este tipo de abordagem mediante estudos que associavam a aprendizagem organizacional e a experiência gerada pela interação com o ambiente, com base no qual a gerência deveria revisar e adaptar as estratégias de desempenho. Embora caiba destacar alguns estudos de Duncan e Weiss, (1979) que colocavam a aprendizagem organizacional como um produto relacional entre açóes dos membros, os resultados consequentes e o efeito que tem no contexto onde se dáo estes processos, estes não conseguiram ultrapassar o paradigma funcionalista, por entender o aspecto relacional como uma variável.

$72 \&$ Universidad de San Buenaventura, Cali - Colombia 
Percebe-se que nestes autores se mantém uma concepção de aprendizagem baseada no Estímulo-resposta e na dinâmica de detectar e corrigir anomalias que pudessem afetar o processo produtivo, sendo este fluxo de açóes o pé de apoio para a reestruturação da estrutura organizacional. Outro grande elemento a identificar principalmente na teoria de Argyris e Schön, (1978) é que estes autores aprofundam o processo da aprendizagem como processo individual dentro da organizaçáo, sendo o conjunto de suposiçóes de cada membro possui e são modificadas em grupo.

Neste ponto histórico de desenvolvimento teórico sobre aprendizagem, poder-se-ia tecer a premissa que as principais investigaçôes e modelos sobre centravam o processo de aprendizagem no indivíduo, o qual era estimulado por condicionamentos ambientais e era entendido como um processo psicológico de mudança.

Com a expansão dos movimentos capitalistas e a reconfiguração de um mercado internacional flexível e instável, os teóricos permitiram uma ampliação epistemológica do conceito de aprendizagem no contexto organizacional. A simples utilização deste tipo de ferramentas comportamentalistas não constituía entáo, uma opção auspiciosa para o desenvolvimento humano e a transformaçáo do sentido do trabalho, considerada como uma visão reducionista que limitava a subsistência das organizaçóes.

$\mathrm{Na}$ continuidade da análise histórica, a perspectiva que conta com a maior aceitação pelos acadêmicos e uma alta produção acadêmica é o cognitivismo. Corrente que desde os anos setenta tem se caracterizado longitudinalmente pela elaboraçáo no contexto organizacional de uma taxonomia de habilidades, competências e condiçôes que propiciam e facilitam mudanças na estrutura cognitiva do indivíduo e o desenvolvimento de estratégias de gestão focalizadas no desenvolvimento individual como meio para o desenvolvimento organizacional (Macksoud, 2002).

Segundo a psicologia cognitiva, a aprendizagem tem um rol vital no desenvolvimento do ser humano em diferentes etapas da vida, além de ser o processo encarregado da formação dos indivíduos como seres sociais. Segundo Vaill, (1996), a aprendizagem implica ação significativa, se caracterizando por ser um processo de conhecer e significar a realidade enquanto se formula o entendimento do mundo. A aprendizagem entáo não é uma atividade isolada, é uma forma de ser no mundo, para este autor a aprendizagem é uma característica ontológica do ser humano.
O cognitivismo é um leque bastante diverso para a criação de teorias e práticas dentro da psicologia organizacional, as principais teses teóricas apontam o indivíduo como centro da cogniçấo, esta premissa pode ser encontrada nas teorias sobre determinantes subjetivos da conduta, sobre as operaçóes cognoscitivas formais, e aquelas que dão ênfase às estruturas e processos internos que representam a formaçáo de ideias, significados e símbolos (Macksoud, 2002).

Já no desenvolvimento de práticas organizacionais associadas com o processo de aprendizagem, são identificadas práticas de adestramento nas organizaçóes, Vaill, (1996) expóe que a aprendizagem é construída a partir de processos e práticas institucionalmente estabelecidas, sendo uma aprendizagem formal e intencionada. Dentro desta abordagem é minimizada a importância das práticas informais dentro do contexto organizacional e aqueles aprendizados, produtos das múltiplas interaçóes dos membros.

Dentro deste tipo de aprendizagem o caráter empirista do processo é frequentemente o eixo central, sendo importantes as características individuais dos aprendizes e as variáveis situacionais, na identificação das contingências nos comportamentos dos sujeitos. Este estudo da aprendizagem na sua dimensão mais instrumental poderia levar a uma profunda omissão dos elementos sociais.

Macksoud, (2002) coloca diferentes exemplos que fazem parte deste adestramento de sujeitos no âmbito organizacional: $\mathrm{O}$ rol da retroalimentaçáo sobre resultados de execução ou desempenho, as socializaçōes em grandes grupos subdivididos segundo características (experiências, conhecimentos, cargos).

Dentro dos levantamentos feitos pela autora surge a premissa interessante da aprendizagem para adestramento, que diz que o processo ocorre de maneira muito mais efetiva, de forma unidirecional, mediante o ensino de experts a amateurs, e possui altos níveis de racionalidade. Aprendizagem organizacional entendida desde este foco deixa um vácuo sobre aquelas aprendizagens que surgem da informalidade de todos os dias e de natureza variada (emocional, intuitivo, afetivo e social) as quais são consideradas exógenas ao processo.

A aprendizagem organizacional para o adestramento deve ser linear, sequencial, eficiente, e dirigida para um objetivo concreto. Como reflexo disso, Macksoud, (2002) apregoa que na psicologia Organizacional a principal conceitualizaçáo da aprendizagem, tem sido amplamente relacionada com práticas de formaçáo e controle de 
pessoas, como parte de estratégias de desenvolvimento organizacional.

Neste sentido os cuidados a ter dentro da pesquisa e pratica do processo de aprendizagem organizacional, tem que visualizar tendências instrumentalizadas do processo, relacionadas com o conhecimento explicito, e em certa medida expressa uma redução da aprendizagem organizacional para adestramento de pessoal, desvirtuando a importância do conhecimento implícito próprio das dinâmicas e significados poucas vezes verbalizáveis.

\section{Epistemologia da aprendizagem organizacional}

Como parte dos eventos sócio-político-econômicos dos anos oitenta, as mudanças internas nas empresas japonesas e seus resultados na competitividade internacional, impulsionaram demandas internas nas empresas ocidentais desencadeando alteraçóes do modelo para organizaçóes estruturalmente mais flexíveis, que a sua vez impactou na consolidaçáo do mercado internacional de capitais e inovaçóes em tecnologia na gestáo da informação e comunicaçóes.

Para entender melhor estas dinâmicas, Prange, (2001) descreve como nos anos 70 a adaptaçáo, os padróes de processamento de informaçóes, o desenvolvimento de teorias para uso organizacional, e a institucionalização da experiência, foram temáticas centrais que estimularam o aumento regular das publicaçóes sobre aprendizagem nas organizaçóes, estimando-se que, na década de 80 , cerca de cinquenta estudos tenham sido publicados em periódicos acadêmicos. $\mathrm{O}$ campo de pesquisa teórico-prático de aprendizagem organizacional teve a sua grande transformação em certa medida alinhada com as reconfiguraçóes que o trabalho teve neste período histórico devido às novas demandas do mercado.

Ante a grande proliferação de estudos, modelos, técnicas e procedimentos sobre aprendizagem organizacional Easterby-Smith e Araujo, (2001) decidiram fazer uma distinção significativa entre autores que estudam a aprendizagem Organizacional, diferenciando-os entre aqueles que analisam o processo como técnico e aqueles que o consideram um processo social.

Segundo as autoras, a visão técnica relaciona a aprendizagem com processamento eficaz, interpretação de respostas e gestão de informações internas e externas de diferente natureza (quantitativa ou qualitativa). Como se pode constatar nos estudos derivados de correntes comportamentalistas e cognitivistas.

Embora as autoras coloquem a palavra técnica para se referir a estudos mais instrumentais da aprendizagem organizacional, é considerado que a palavra poderia apresentar certas limitaçôes, já que a visão descrita pelas autoras consegue transcender para aspectos teóricos e ideológicos fundamentais sobre o que é aprender nas organizaçôes, os quais enxergam o processo conjunto de ferramentas que têm como objetivo obter um determinado resultado.

Esta perspectiva técnica goza do respaldo e preferência por parte do discurso gerencial porque permite cálculos mais exatos da dinâmica organizacional, e a ênfase pelo processamento de informação em diferentes formas de gestão gerencial. Colocar centralidade na informação como bem intangível do grupo atua de forma paradoxal, já que se pode utilizar para estimular os funcionários a gerar conhecimentos e obter graus de autonomia e liberdade, $\mathrm{e}$ por outro lado pode ser utilizadas de maneira seletiva, de controle e alienação dos membros da organização.

Nesta última premissa podem-se identificar uns dos principais problemas que se encontra nessa perspectiva técnica sinalada por Easterby-Smith, e Araujo, (2001), relacionado com o uso inapropriado ou manipulado da informação, quando esta mostra conteúdos e ideologias dos gerentes os quais distorcem e suprimem dados para apoiar seus pensamentos, açóes e validação de decisôes.

Em contrapartida a perspectiva técnica abordada até este ponto, as autoras expóem aqueles estudiosos da Aprendizagem organizacional os quais apregoam uma perspectiva social. Esta perspectiva apoiada em conceiçóes mais recentes da aprendizagem organizacional desde a Psicologia expóe que o processo de aprendizagem dentro das organizaçôes esta baseado nas inter-relaçôes dos membros e que emerge das relaçóes e das construçôes sociais da dinâmica de trabalho.

A importância desta perspectiva atinge nas experiências de aprendizagem que podem derivar de fontes explícitas ou fontes implícitas (tácitas). Desde esta perspectiva a aprendizagem é algo que emerge de interaçôes sociais e sua disseminação e institucionalização depende tanto do sujeito como da organização, (Nonaka \& Takeuchi, 1995).

Orr, (1990) tece que muito do conhecimento crítico dentro das equipes de trabalho não existe no papel, nem exclusivamente na mente dos indivíduos, a sua principal importância está na comunidade como conjunto. Segundo o autor o processo de aprendizagem é completamente 
flexível na medida em que acontece tanto por meio da expansão da comunidade, na incorporação de novos membros, como pela adoção de novas formas de comportamento e práticas não escritas.

É importante salientar que a relação entre conhecimento explícito e tácito criados pelos membros da organização envolve um processo compartilhado, onde eles retiram e constroem significados destes dados, que dentro de um processo de aprendizagem bem sucedido são incorporados pelos membros mediante as práticas estabelecidas emulação de profissionais competentes e socialização em comunidades de práticas.

Em conclusão pode-se ressaltar que o crescimento teórico da aprendizagem organizacional, caracteriza-se por ser multiparadigmatico, com elementos e autores que apresentam posturas tanto epistemologias como ontologias diversas sobre o ato de aprender. Ante esta realidade se decide tomar um posicionamento teórico dentro deste amplo leque teórico, Adoptando um análise da aprendizagem como processo psicossocial inscrito e articulado em práticas e modelos de trabalho contemporâneos como é o caso do empreendedorismo social, articulaçáo que se passará a analisar seguidamente.

\section{Conceptualização do empreendedorismo social}

Os empreendedorismos sociais são iniciativas, programas ou organizaçóes criados para promover mudanças sociais através de projetos ou açóes que têm como objetivo principal a geração de valor social para um grupo de pessoas, uma comunidade ou um território, mobilizando diferentes e diversos atores e recursos. Esta definiçáo foi sintetizada fundamentando-se nas proposiçôes dos diversos autores e linhas que versam sobre o tema (Bose, 2004; Ashoka 2001; Nicholls, 2006; Dees, 2001; Johnson, 2000).

O termo empreendedor social e empreendedorismo social são traduçôes de termos originários da língua francesa social entrepreneur e social entrepreneurship que significam: Aquele que assume riscos e começa algo novo. Estes conceitos foram utilizados pela primeira vez em inglês entre as décadas de 1960 e 1970. Entretanto, o termo foi de fato disseminado não seria melhor durante as décadas de 1980 e 1990 por Bill Drayton, o fundador da Ashoka, Empreendedores Sociais, e pelo escritor inglês Charles Leadbeater.
O empreendedorismo social como agenciamento é novo em sua atual configuração, embora algumas das suas características fossem tempos atrás identificadas em grandes personalidades como Luther King, Gandhi, entre outros devido às capacidades de liderança e inovação ante mudanças sociais em larga escala. Nesta revisão, uma das primeiras constataçóes foi a pouca bibliografia sobre o assunto, não somente no Brasil e na Colômbia como também no exterior, o que demonstra tratar-se de um tema incipiente que ainda em desenvolvimento.

O empreendedorismo social surge da constataçáo do crescimento das organizaçóes do terceiro setor, da diminuição do investimento público na questão social e da participação crescente das empresas no campo social.

Oliveira, (2003) Expóe que hoje em dia existe um grande desconhecimento sobre diferenciaçáo entre Empreendedorismo empresarial e Empreendedorismo social, sendo necessário distinguir a prática do empreendedorismo empresarial da prática do empreendedorismo social, vemos entáo que o empreendedorismo empresarial tem o foco no mercado enquanto o empreendedorismo social tem o foco na busca de soluçóes para os problemas sociais.

Enquanto o primeiro utiliza o lucro como medida de desempenho, no empreendedorismo social a medida de desempenho é o impacto provocado na sociedade. Por fim, enquanto o empreendedorismo empresarial visa satisfazer as necessidades dos clientes e ampliar as potencialidades do negócio, o empreendedorismo social visa a respeitar pessoas da situação de risco social e a promovê-las.

Outros autores como Silva e Dutra, (2004) expóem que as características centrais do empreendedorismo social seriam: a) adoção de uma orientação (ou missão) voltada para a criação e manutenção do valor social (diferentemente do valor econômico); b) identificaçáo e procura de novas oportunidades de empreendedorismos que viabilizem a consecuçáo da missão da organização; c) engajamento no processo de inovação, adaptação e aprendizado contínuo; d) ação corajosa em face da limitaçẫo de recursos com que se defrontam geralmente as organizaçóes do Terceiro Setor; e) demonstração de um elevado senso de responsabilidade cívica para com os segmentos de público com os quais a organizaçấo está envolvida e a conseqüente sustentabilidade dos resultados obtidos.

Com base nas múltiplas definições expostas pelas organizaçôes e autores revisados é possível sintetizar oito características que convergem na análise das diferentes definiçóes sobre Empreendedorismo social: 
- É coletivo e integrado;

- Tem o foco na busca de soluçóes para os problemas sociais e necessidades da comunidade;

- A medida de desempenho é o impacto e a transformaçáo social;

- Visa a resgatar pessoas da situaçáo de risco social e promovê-las, a gerar capital social, inclusão e emancipação social;

- Produz bens e serviços para a comunidade local e global;

- Os sujeitos inscritos nesta dinâmica podem possuir características do empreendedor tradicional, porém voltadas às inovaçóes sociais;

- Transcendem o paradoxo Público-Privado;

- A liderança é uma característica da relação entre os membros da equipe;

O empreendedorismo social em parte devido a estas características articula uma nova configuração do trabalho, segundo Oliveira (2004) o modelo propóe mudanças fundamentais na forma e conteúdo do trabalho:

Primeiro, a aplicação do empreendedorismo social propicia e incentiva não só a criação de formas de gestão organizacional, mas também novas formas de relação das pessoas envolvidas com vários segmentos da sociedade, os membros desse tipo organização se caracterizam por serem agentes de mudanças, reformadores e revolucionários com uma missão social.

Como segundo ponto o autor coloca o empreendedorismo como um meio propulsor de açóes inovadoras, dinamiza e estimula a integração, a cooperação e a autosustentabilidade das organizaçóes, de seus gestores e dos serviços e produtos que oferece, gerando o principal elemento na atualidade para impulsionar açóes transformadoras, o capital social.

Terceiro, as organizaçóes diferem das organizaçóes do primeiro setor (privadas - mercado- lucro) e das Governamentais (Estatais, municipais, federais, autarquias, etc.), o que gera uma forma de auto-organizaçáo social, afetando o modo de conservaçáo histórico de tratamento da pobreza e demais problemas sociais.

Finalmente por quarto ponto, o impacto de suas açôes possui a potencialidade de gerar emancipaçáo social; Contribuem significativamente para melhorar a compreensão do fenômeno dos problemas sociais, bem como, da abertura de novos olhares da complexidade dos problemas sociais, não sendo somente econômicos, mas também referentes à conduta social, ao uso correto dos recursos e conhecimentos para uma melhor aplicação e resultados mais significativos.

\section{Aprendizagem organizacional processo psicossocial inscrito no empreendedorismo social}

A visão de aprendizagem organizacional desde uma perspetiva social possibilita entender o processo como interação, construção e interpretação de símbolos e significados compartilhados. Berger e Luckmann, (1966) argumentam que as pessoas que interagem com um determinado contexto social construem conhecimento social, o qual é um filtro pelo qual elas enxergam problemáticas e julgam comportamento e atitudes.

Desde este apontamento teórico, pensar nos processos, fontes e métodos de aprendizagem dos indivíduos inscritos na dinâmica do empreendedorismo social, possibilitaria a identificação de ferramentas e estratégias organizacionais para aperfeiçoar e fortalecer as açóes por meio da melhor compreensão e conhecimento das práticas que perseguem objetivos de transformação social.

Por outro lado, propor um tipo de aprendizagem que não se baseia em aprendizagens individuais, facilita a compreensão dos padróes de associaçóes cognitivas e a mudança comportamentais.

Na mesma linha Weick e Roberts, (1993) formulam um tipo de aprendizagem organizacional que consiste em açóes inter-relacionadas de indivíduos, ou seja, uma inter -relaçáo de indivíduos que resulta em uma mente coletiva com alta potencialidade de impacto e internalização de valores e objetivos organizacionais.

No empreendedorismo social o processo de aprendizagem organizacional estaria amplamente relacionado com a dinâmica dos grupos, as práticas discursivas e a construçáo de significados, tanto nos processos, tanto na modificação nas práticas de trabalho. Macksoud, (2002) ressalta a importância do empowerment no trabalho e a necessidade de participaçáo cada vez maior dos colaboradores para tomada de decisóes, e a necessidade que para que isso aconteça se requere que se desenvolvam novos modelos mentais e novas formas de interaçóes com o mesmo problema social. 
Abordar aprendizagem organizacional como processo inscrito na dinâmica do empreendedorismo social focaliza na capacidade estratégica do conhecimento construído significativamente, histórias coletivas, linguagens, modelos mentais para uma comunidade em particular. Uma organização empreendedora com fins sociais que Aprende, gera e dissemina conhecimentos e ideologias para melhorar as práticas e programas sociais, figuraria como uma organização criadora de conhecimentos que além de atuar com eficácia garante autonomia dos membros.

Pensar uma organizaçáo empreendedora socialmente, como uma organizaçáo que possibilita autonomia dos membros e q criaçáo de conhecimento, é segundo Nonaka e Takeuchi, (1995) um sistema autopoietico utilizando o termo acunhado por Maturana e Varela em 1980, explicando que os sistemas orgânicos vivos são compostos por vários órgáos e no mesmo tempo por milhares de células. Entre membros e entre células existem relacionamentos que não poderiam se categorizar como do tipo dominado-subordinado, tampouco de tipo global. Os autores entendem que casa unidade e cada célula é autônoma, com capacidade de controlar todo o que acontece no seu interior.

Estas unidades têm fronteiras que são autodeterminadas, dando preferência às necessidades que aparecem no seu desenvolvimento. Da mesma forma que o sistema autopoietico os indivíduos são autônomos e os grupos demarcam suas fronteiras e metas de desempenho. Este processo de autonomia nos indivíduos e grupos permite processos táo necessários no empreendedorismo social como são a eficácia para atingir os objetivos e metas sociais e a inovação, característica central e diferencial que pode ser fortalecida e dinamizada pelas constantes trocas de experiências e aprendizados dos membros da organizaçáo e da organização com a comunidade foco de trabalho.

\section{Referências}

Antonello, C. S. (2005). A metamorfose da aprendizagem organizacional: uma revisão crítica. In R. Ruas, C. S. Antonello \& L. H. Boff (Orgs.), Aprendizagem organizacional e competências (pp. 12-33). Porto Alegre: Artmed.

Argyris, C., \& Schön, S. (1978). Organizational Learning: A theory of Action Perspective. MA: Addison-Wesley.

Ashoka empreendedores sociais., \& McKinsey e Company. (Eds.). (2001). Empreendimentos sociais sustentáveis. São Paulo: Peirópolis.

Bandura, A. (1982). Teoría del aprendizaje social. Madrid: Espasa-Calpe.
Bose, M. (2004). Gestão de pessoas no terceiro setor (Dissertação de Mestrado). Universidade de São Paulo, Brasil.

Dees, J. (2001). The Meaning of Social Entrepreneurship. Recuperado de https://goo.gl/jHlagx

Dodgson, M. (1993). Organizational learning, a review of some literatures. Organization Studies, 14(3), 375-394.

Duncan, R. B., \& Weiss, A. (1979). Organizational Learning: Implications for Organizational Design. En B. Staw (Ed.), Research in Organizational Behavior (pp. 75-123). Greenwitch- CT: Jaipress.

Easterby-Smith, M., \& Araujo, L. (2001). Aprendizagem organizacional: oportunidades e debates atuais. In M. Easterby-Smith, J. Burgoyne \& Araujo, L (Eds.), Aprendizagem organizacional e organizaçóes de aprendizagem: desenvolvimento na teoria e na prática (pp. 15-34). São Paulo: Atlas.

Feist, G., \& Feist, J. (2008). Teorias da Personalidade. São Paulo: McGraw-Hill.

Fiol, C. M., \& Lyles, M. A. (1985).Organizational Learning. Academy of management review, 10(4), 809-813.

Giddens, A. (2002). Modernidade e identidade. Rio de Janeiro: Jorge Zahar.

Hergenhan, B. R. (1982). An introduction to theories of Learning. NJ: Prentice-Hall.

Johnson, S. (2000). Literature review on Social Entrepreneurship. Canada: Canadian Centre for Social Entrepreneurship.

Loila, E., \& Bittencourt, A. V. (2005). A produção acadêmica sobre Aprendizagem Organizacional no Brasil. $R A C, 7$, 181-201.

Macksoud, S. (2002). El aprendizaje como cognición social en la experiencia del trabajo al nivel organizacional. Puerto Rico: Psychikós.

Marcuse, H. (1983). Eros y Civilización. Madrid: Sarpe.

Nicholls, A. (2006). Playing the field: A new approach to the meaning of social entrepreneurship. Social Enterprise Journal, 2(1), 1-5.

Nonaka, I., \& Takeuchi, H. (1995). The Knowledge-creating Company. Oxford, UK: Oxford University Press.

Oliveira, E. M. (2003). Empreendedorismo social no Brasil: fundamentos e estratégias (Tese de Doutorado). Universidade Estadual Paulista, São Paulo.

Oliveira, E. M. (2004). O empreendedorismo social indutor de auto-organização no enfrentamento das questóes sociais e no desenvolvimento integrado e sustentável: notas introdutórias e aproximativas-notas introdutórias. Informe GEPEC, 8(1), 1-17.

Orr, J. (1990). Talking about machines: An ethnography of a modern job. NY: Cornell University. 
Pawlowsky, P. (2001) .The treatment of Organizational Learning in management science. In M. Dierkes, A. Berthoin Antal, J. Child \& I. Nonaka (Eds.), Handbook of Organizational Learning and Knowledge (pp. 61-88) Oxford: Oxford University Press.

Piaget, J. (1986). A epistemologia genética. São Paulo: Editora Abril S.A.

Prange, C. (2001). Aprendizagem organizacional: desesperadamente em busca de teorias. In M. Easterby-Smith, J. Burgoyne \& L. Araujo (Orgs.), Aprendizagem organizacional e organizaçóes de aprendizagem: desenvolvimento na teoria e na prática (pp. 41-63). São Paulo: Atlas.

Rosero, O. (2009). Emprendimiento y aprendizaje organizacional: Tendencias y perspectivas desde la psicologia organizacional y del trabajo (Tesis de maestría inédita). Universidad del Valle, Cali-Colombia.

Silva, H. E., \& Dutra, M. 1. (2004). Talento empreendedor brasiliense: uma proposta de aprendizagem para os cursos de Administração. Trabalhoin oferecido na conferência de Internacional de pesquisa em empreendedorismo na América Latina, Rio de Janeiro-Brasil.

Singer, P. (1997). Practical Ethics. Cambridge: Cambridge University Press.

Singer, P. (2004). Um olhar diferente sobre a economia solidária. In: G. C. França-Filho \& J. L. Laville (Eds.), A economia solidária: uma abordagem internacional (pp. 198-214). Porto Alegre: Editora da UFRGS

Souza-Silva, J., \& Schommer, P. C. A. (2008). Pesquisa em comunidades de prática: panorama atual e perspectivas futuras. Organizaçôes e Sociedade, 15(44), 105-127.

Vaill, P. (1996). Learning Away of Being. CA: Jossey-Bass Publishers.

Weick, K. E., \& Roberts, K. H. (1993). Collective mind in organizations: heedful interrelation on flight decks. Administrative Science Quarterly, 46(43), 81-357. 